\title{
O DOMÍNIO LINGUÍSTICO DE DOCENTES NA PRÁTICA DE ENSINO
}

\author{
Rogerio do Amaral ${ }^{1}$, Kátia Roberta Rodrigues-Pinto ${ }^{2}$ \\ ${ }^{1}$ Doutor em Educação, pela Universidade Estadual Paulista - UNESP, Presidente Prudente, SP. Docente da \\ Universidade do Oeste Paulista - UNOESTE, Presidente Prudente, SP. E-mail: rgamaral@unoeste.br \\ ${ }^{2}$ Especialista em Estudo da Gramática da Língua Portuguesa pela Universidade do Oeste Paulista - UNOESTE, \\ Presidente Prudente, SP. Docente da Escola da Administração Penitenciária SP - Secretaria da Administração \\ Penitenciária. E-mail: katiarodriguespinto@gmail.com
}

\section{RESUMO}

Este artigo objetivou, por meio de um estudo qualitativo, analisar a prática de ensino dos professores, através da oralidade e escrita, em uma escola estadual do município de Mirandópolis no Estado de São Paulo, observando o conhecimento linguístico aplicado em sala de aula como instrumento mediador de ensino e aprendizagem aos alunos. Partindo da premissa que docentes licenciados em Letras e habilitados em lecionar a língua portuguesa já possuem tal conhecimento das regras que regem a norma culta, as variantes linguísticas e linguagem, fez-se necessário pontuar e investigar como professores de outras disciplinas atuam utilizando e dominando a língua portuguesa como facilitadora de compreensão dos conteúdos trabalhados. A metodologia aplicada se baseia no estudo de campo, estudo da área (ambiente físico), pesquisa bibliográfica, registro fotográfico, entrevista com aplicação de questionário englobando diretamente onze pessoas, sendo uma coordenadora pedagógica, quatro professores e seis alunos, além de indiretamente envolver alunos regulares do Ensino Médio no qual se realizou a pesquisa de campo. Os resultados obtidos e confirmados são elucidados ao longo deste artigo e expressam claramente a relação entre alunos e professores quanto ao interesse e assimilação dos conteúdos propostos em sala de aula. Conclui-se que saber se comunicar e se fazer entender é de extrema necessidade quando falamos em prática de ensino e didática aplicada. Tais habilidades dar-se-ão através do prévio conhecimento e domínio na nossa língua.

Palavras-chave: Prática de Ensino. Linguagem. Ensino e Aprendizagem. Língua Portuguesa. Conhecimento Linguístico.

\section{THE TEACHER'S LINGUISTICAL DOMAIN IN TEACHING PRACTICE}

\begin{abstract}
This article has the objective to present through a quantitative research the analysis and pratice of teachers education methods by the oral and writing pratice in a goverment school located in Mirandopolis city, Sao Paulo, Brazil, observing the linguist knowledgement applied in classroom as a student's teaching and learning moderator instrument. From the point that Modern Languages gratuated teachers are able to teach in Portuguese language and they already have knowledge of the rules which correspond to the cultured norms, the linguistics and and language variations; it is necessary to point and investigate how teachers from another subjects used to act by using and dominating the Portuguese language as an easy way to understand the elaborated contents. The metodology applied in this article is based on the field and physical place studies, bibliography reaseach, photography records, interviews with a questionary involving eleven people directly such as a pedagogical coordinator, four teachers and six students and also involving indirectly regular students from high school where the field study has been developed. The obtained and confirmed results are explained along this article and they clearly express the relation between students and teachers about the interest and absortion of the contents that are proposed in classroom. It concluded that it is extremely necessary to know how to comunicate and to be understanding when it is talking about teaching pratice and applied didactic. These habilities will only happen by the previous knowledge and the Portuguese language domain.
\end{abstract}

Keywords: Teaching Practice. Language. Teaching and Learning. Portuguese Language. Linguistic proficiency. 


\section{INTRODUÇÃO}

Um dos maiores desafios a quem se propõe enveredar pelo caminho da docência é trabalhar conteúdos curriculares com eficiência e didática necessária para despertar interesse nos alunos e movê-los a construir ideias próprias tornando-os cidadãos pensantes e críticos. Tarefa essa de suma importância e de grande complexidade, principalmente, quando se refere à didática cujo conceito primário a define como uma gama de estratégias com finalidade de colocar em prática métodos de ensino $\mathrm{e}$ aprendizagem.

O objeto desta pesquisa foca, essencialmente, como a Língua Portuguesa, com a variante linguística denominada norma culta, pode contribuir enquanto instrumento e meio didático, no processo de ensino e aprendizagem nas mais variadas áreas de conhecimento e, consequentemente, matérias lecionadas no ensino médio como etapa final da educação básica. Definida por Brandão (apud COSERIU, 1979), entende-se como norma culta "a modalidade escrita empregada na escola, nos textos oficiais, científicos e literários. Baseada na tradição gramatical, é a variante de maior prestígio sociocultural."

Outras definições são atribuídas a esta modalidade linguística por conceituados gramáticos em suas obras. Cunha e Cintra (apud BAGNO, 2012, p. 22) relatam que: "Trata-se de uma tentativa de descrição do português atual na sua forma culta, isto é, da língua como a têm utilizado os escritores portugueses, brasileiros e africanos do Romantismo para cá". Assim como Bechara (apud BAGNO, 2012, p. 22) explica: "A gramática normativa recomenda como se deve falar e escrever segundo o uso e a autoridade dos escritores corretos e dos gramáticos e dicionaristas esclarecidos."

Para a grande maioria das pessoas, tratase do uso rebuscado e erudito do vocabulário pertencente a uma classe socialmente privilegiada. Acerca disso, aponta Bagno (2012, p. 21)

[...] seria aquele conjunto de regras e preceitos de que aparece estampado nos livros chamados gramáticas. Por sua vez, essas gramáticas se baseariam, supostamente, num tipo peculiar de atividade linguística exclusivamente escrita - de um grupo muito especial e seleto de cidadãos, os grandes estilistas da língua [...]. Inspirados nos usos que aparecem nas grandes obras literárias, sobretudo do passado, os gramáticos tentam preservar esses usos compondo com eles um modelo de língua, um padrão a ser observado por todo e qualquer falante que deseje usar a língua de maneira "correta", "civilizada", "elegante" etc. É esse modelo que recebe, tradicionalmente, o nome de norma culta.

Há teorias linguísticas modernas que condenam a gramática tradicionalista como abstrata ao cotidiano e irreal aos usuários da língua, assim como explana Junqueira (apud BRITTO, 2002, p. 147) "não é falada por quase ninguém e mesmo as pessoas instruídas e de boa condição social erram com relação à gramática". Chega ao extremo sarcástico, ao ironizar, quando relata Bagno (1999, p. 69 ):

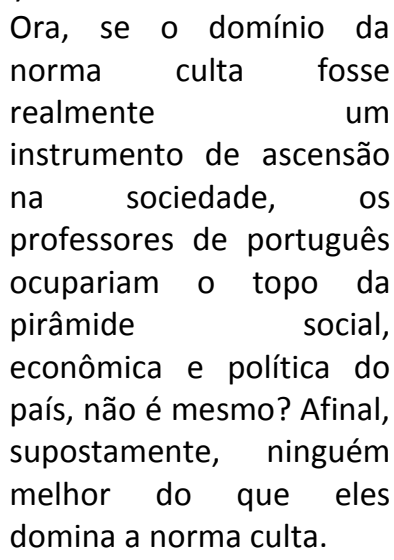

Contudo, valer-se do padrão culto é utilizar linguagem simples, de fácil compreensão, objetiva e denotativa. Erroneamente, pensa-se que para escrever e falar "corretamente", é necessário palavras de difícil compreensão que provoque admiração entusiasta no interlocutor.

Deve-se priorizar o que determinam as regras gramaticais com a finalidade de oferecer ao ouvinte, nesse caso, o aluno, a oportunidade de acessar novos horizontes culturais. Bechara (2011) defende a ideia de que privar as pessoas ao acesso à norma culta é o mesmo que negarIhes uma chance de progredir na vida. A esse 
mesmo autor, cujo prestígio é indiscutivelmente grandioso, quando the foi perguntado como o domínio disseminado da norma culta da língua pode contribuir para o avanço do país, o mesmo discursou:

Antes de tudo, formando cidadãos mais capacitados para preencher vagas que demandem alta qualificação, algo crucial para a economia. Ao questionar a necessidade do estudo da gramática nas escolas do país, linguistas como Marcos Bagno e tantos outros estão nivelando por baixo o ensino do português. Acabam reduzindo com isso as chances de milhões de estudantes aprenderem a se expressar com correção e clareza, tanto na escrita quanto na fala. A história reforça a importância disso. Ela é farta em exemplos de como uma oratória eficaz, por exemplo, pode catapultar carreiras. (BECHARA, 2011, p.22)

O educador não pode desconsiderar que o aluno está em processo de formação. Ele detém conhecimento que foi adquirido através do seu meio social, pois é usuário da língua utilizando-a na sua forma coloquial, como define Brandão (apud COSERIU 1979) "é aquela empregada oralmente pelas classes médias escolarizadas. Viva e espontânea, seu grau de desvio em relação à norma gramatical é maior, caracterizando o chamado 'erro'." Contudo, como rebate Ribeiro $(2013$, p.9)

O professor é uma referência para os alunos, principalmente se for, de fato, usuário da língua, tendo boa relação com a leitura, além de ensinar, mostra a relação que tem com os textos e o valor que a linguagem tem de possibilitar o acesso a usos da linguagem mais formalizados, porque ensinar a língua não significa trabalhar a capacidade de falar em geral, significa desenvolver o domínio de gêneros.

Docentes que ministram as disciplinas de matemática, biologia, química, sociologia, educação física e história, por exemplo, podem se apropriar dos fundamentos da normativa culta para levarem aos alunos a importância que a língua materna tem e, eles próprios, servirem de referencial como profissionais e educadores membros da sociedade que utilizam devidamente as diversas formas de linguagem. Sabe-se que a comunicação estreita laços e aproxima o ser humano, que a linguagem falada e escrita compõem ferramentas básicas na mediação de conhecimento em sala de aula, assim, nada mais educativo do que fazer o uso culto da língua para transmitir aos alunos a importância social que essa variante linguística tem na sua formação individual enquanto pessoas capazes de formularem seus próprios pensamentos, como ressalta Ribeiro (apud MENDES et al., 2011, p. 29): "Inseridos no contexto que vivemos e na realidade manifesta em nosso país, devemos criar condições para que os alunos se tornem cidadãos que pensem e atuem por si mesmos".

Considerando tais informações, pode-se através deste estudo, observar a fragilidade do domínio linguístico dos docentes tanto na oralidade quanto na escrita, na exposição e transmissão dos conhecimentos trabalhados em sala de aula. Nota-se, claramente, que existe certo grau de dificuldade por parte dos docentes, das matérias supracitadas e analisadas, em aplicar a norma culta da língua como parte significativa e exemplar no âmbito escolar. A gramática poderia ser utilizada como meio expressivo de entendimento, porém a sua utilização inadequada, não desperta interesse no aluno, como afirma Ribeiro (apud KAESKI; AVER, 2014, p. 4) "A falta de dimensão afetiva dos professores com a gramática dificulta a defesa do seu ensino e o esforço por parte do aluno. Nesse ambiente com pouca estimulação, [...] desencadeia-se um sentimento de aversão e repulsa pela gramática."

Observa-se a importância que o tema em análise aponta quanto à formação de profissionais educacionais comprometidos e conscientes sobre o seu papel de construção do saber oferecido aos alunos. Vale ressaltar novamente a importância de respeitar a bagagem 
cultural intrínseca trazida pelo discente do seu meio social, como é garantido pelos Parâmetros Curriculares Nacionais, quando diz:

Toda educação
comprometida com o
exercício da cidadania
precisa criar condições
para que o aluno possa
desenvolver sua
competência discursiva.
[...] Um dos aspectos da
competência discursiva é o
sujeito ser capaz de
utilizar a lingua de modo
variado, para produzir
diferentes efeitos de
sentido e adequar o texto
a diferentes situações de
interlocução oral e escrita.
(MEC, 2000, p.83)

Porém, como define o guia de Orientações curriculares para o Ensino Médio:

[...], essa fase de estudos deve ser compreendida como período de consolidação e aprofundamento de muitos dos conhecimentos construídos ao longo do ensino fundamental. Espera-se, portanto, dessa etapa de formação o desenvolvimento de capacidades que possibilitem ao estudante: (i) avançar em níveis mais complexos de estudos. (MEC, 2006, p.17)

Sobre o momento crucial e fundamental para intensificar a avaliação do nível de percepção de conhecimento por parte dos alunos no ensino médio, Ribeiro (apud MENDES et al., 20011 , p. 29) traduz que: "A simplificação do tratamento dado à gramática - superficialidade traz como consequência observável a dificuldade de incorporação dos novos conceitos ao referencial teórico que o aluno já tem". É válido esclarecer que tal simplificação, infelizmente, ocorre pela insuficiência de habilidade teórica do educador.

Muitos teóricos apontam os temas transversais como alternativas para a aproximação do ensino da língua portuguesa. Assim, entende-se que trabalhar gramática dissolvida em outras disciplinas garantiria a excelência e o entendimento do que está sendo discutido e ensinado com uma abordagem culta e reflexiva. De pouco valeria o pensamento construtivista de formar indivíduos críticos e aptos a viverem em sociedade, se esses não souberem se posicionar diante das mais variadas ocasiões que necessitam de compreensão e uso adequado das variantes linguísticas, inclusive, da norma culta.

O objetivo deste estudo consiste em, não somente apontar a fragilidade do domínio linguístico em métodos de ensino e aprendizagem dos conteúdos oferecidos por professores de todas as áreas de conhecimento no ensino médio, mas entender o porquê da resistência em utilizar a norma culta como variante linguística essencial para formação de indivíduos letrados com capacidade interpretativa do mundo.

\section{MATERIAIS E MÉTODOS}

Quanto à metodologia, utilizou-se pesquisa de cunho qualitativo, elucidado por Chizotti (apud PIANNA, 2009, p.168) por ser
A abordagem qualitativa parte do fundamento de que há uma relação dinâmica entre o mundo real e o sujeito, uma interdependência viva entre o sujeito e o objeto, um vínculo indissociável entre o mundo objetivo e a subjetividade do sujeito. o conhecimento não se reduz a um rol de dados isolados, conectados por uma teoria explicativa; o sujeito-observador é parte integrante do processo de conhecimento e interpreta os fenômenos, atribuindo- Ihes um significado. $\mathrm{O}$ objeto não é um dado inerte e neutro, está possuído de significados e relações que sujeitos concretos criam em suas ações.

Com o propósito de reconstruir o aparato metodológico utilizado nesta pesquisa utilizou-se como instrumentos, a coleta de dados por meio da observação do ambiente em campo (sala de aula), estudo da área (ambiente físico da unidade 
escolar), entrevista com aplicação de questionário formulado pela autora deste artigo, registro fotográfico e pesquisa bibliográfica.

Teve-se como campo investigativo uma escola estadual na cidade de Mirandópolis no Estado de São Paulo, aqui intitulada pelas iniciais E. E. N. D. P. Essa oferece ensino de nível fundamental, médio e profissionalizante com espaço amplo, sala de leitura arejada com equipamento de multimídia, biblioteca com um acervo diversificado de obras e títulos, sala de informática equipada com computadores disponíveis aos estudantes e quadra coberta para o desempenho de atividades físicas.

A pesquisa em campo (observação do ambiente) é definida, segundo Chizotti (apud PIANNA, 2009, p.168), como

[...] o tipo de pesquisa que
pretende buscar a
informação diretamente
com a população
pesquisada. Ela exige do
pesquisador um encontro
mais direto. Nesse caso, o
pesquisador precisa ir ao
espaço onde o fenômeno
ocorre, ou ocorreu e
reunir um conjunto de
informações a serem
documentadas [...].

O conjunto de informações, supramencionado, refere-se a coleta de dados obtidos por meio da observação das aulas assistidas e acompanhadas com o propósito de aproximação do objeto pesquisado.

Tal pesquisa foi realizada em cinco dias, com um total de vinte horas-aula, sempre no período da manhã, onde se pôde assistir às aulas de: matemática ( $3 \circ$ ano), química ( $2 \circ$ ano), biologia ( 10 ano), história ( 20 ano), sociologia ( 1 은 ano), artes ( $2 \circ$ ano) e educação física ( 3 ano), do ensino médio regular e técnico.

Para garantir uniformidade quanto à coleta de informações e impulsionar a discussão sobre 0 assunto focando alcançar 0 entendimento entre as partes envolvidas, necessitou-se da aplicação individual de um questionário escrito onde foram formuladas cinco perguntas abertas para cada grupo. Essas foram confeccionadas, pela autora do artigo, visando analisar como cada grupo entende a importância de dominar e compreender a língua materna dentro do contexto e âmbito escolar, além da sua utilidade social. Aplicou-se perguntas abertas porque possibilitam, aos entrevistados, liberdade de expressarem suas opiniões e a promoção de espaço para novas argumentações.

Denominou-se como grupo 1 , os docentes cuja experiência profissional é, em média, de dez anos sendo dois professores e duas professoras; grupo 2, os alunos com idade entre quinze e dezoito anos, onde três são do sexo masculino e três do sexo feminino e grupo 3 finalizando com a coordenadora pedagógica que trabalha na área há alguns anos e possui experiência docente.

A entrevista foi utilizada como um dos instrumentos de coleta de informações, direta na fonte pesquisada, para aprofundamento investigatório quanto à oralidade entre as partes envolvidas. Segundo Brito Junior e Feres Junior (apud RIBEIRO, 2011, p.239) a entrevista é

A técnica mais pertinente quando $o$ pesquisador quer obter informações a respeito do seu objeto, que permitam conhecer sobre atitudes, sentimentos e valores subjacentes ao comportamento, o que significa que se pode ir além das descrições das ações, incorporando novas fontes para a interpretação dos resultados pelos próprios entrevistadores.

A aplicação desse instrumento, a entrevista, foi gravada e ocorreu de maneiras distintas sem exigibilidade de duração de tempo ou mesmo cronometrado, no entanto, a média de tempo foi de 15 minutos. Com o grupo 1 (discentes) foi realizado em grupo aberto, com todos os entrevistados juntos propositalmente, uma vez que nessa faixa etária, os adolescentes se sentem mais à vontade e abertos a questionamentos quando estão inseridos em seu meio de convívio, sua "tribo" como eles mesmos se referiram. Já com os grupos 2 (docentes) e grupo 3 (coordenadora pedagógica), a abordagem ocorreu individualmente por questões éticas e com o propósito de permear a prática docente de cada um.

Notifica-se que houve registro fotográfico das dependências da instituição de ensino, bem como dos alunos e professores. Também sobre a realização de projetos como Escola da Família e 
aula voluntária, por esta autora, de redação para alunos que realizaram o ENEM. Entretanto, conclui-se que não seria pertinente e nem relevante para conclusão fundamentada sobre o objetivo da pesquisa. Cabe aqui apenas a informação de que as fotos foram coletadas durante a pesquisa de campo por docentes e a pesquisadora com o intuito de gerar dados para pesquisa, assim como, provocar proximidade com os alunos. O critério adotado foi de registrar a rotina escolar.

Pôde-se estabelecer parâmetros de análise e fundamenta-los com pesquisa bibliográfica quanto ao objeto deste estudo por intermédio dos dados coletados.

\section{RESULTADOS}

Por mérito do material empírico coletado, constatou-se que existem pontos relevantes que precisam ser trabalhados para garantir uma didática eficiente e concreta no processo de ensino e aprendizagem. Um desses pontos se diz no próprio entendimento do que é didática. Segundo Comenius (1632) didática se baseia na arte de ensinar em seu caráter pedagógico. Porém, entende-se que essa prática evolui e ganhou significados mais abrangentes. Libâneo $(2002$, p. 26) aponta como premissa da escola e do ensino hoje, o seguinte parâmetro:

A razão pedagógica, a
razão didática, está
associada à aprendizagem
do pensar, isto é, a ajudar
os alunos se constituírem
como sujeitos pensantes,
capazes de pensar e lidar
com conceitos, para
argumentar, resolver
problemas, para se
defrontarem com dilemas
e problemas da vida
prática. Democracia na
escola hoje, justiça social
na educação, chama-se
qualidade cognitiva e
operativa do ensino.

Para ativar esse processo, necessitar-se-ia que os professores tivessem a consciência pedagógica de que, independentemente da matéria que lecionam, a língua portuguesa deveria ser respeitada e trabalhada em sala de aula como fundamento primordial para alcançarem os objetivos propostos e sugeridos pela Lei de Diretrizes e Bases da Educação
Nacional (BRASIL, 1996), "Art.22. A educação básica tem por finalidades desenvolver 0 educando, assegurar-lhe a formação comum indispensável para o exercício da cidadania e fornecer-lhe meios para progredir no trabalho e em estudos posteriores."

Os PCNs afirmam que essa é uma prática que precisa ser adotada. "Na realidade, o aprendizado das Ciências da Natureza e da Matemática deve se dar em estreita proximidade com Linguagens e Códigos, assim como com as Ciências Humanas." (BRASIL, 2000, p. 10). Considerando essas informações que servem para nortear o compromisso educacional da escola e o papel do professor, Ribeiro $(2013$, p. 8 9) defende que:

A escolar precisa
proporcionar momentos
de reflexão para que o
aluno tenha condições de
escolher a forma de falar e
de escrever, utilizando os
recursos e os estilos em
diferentes situações
comunicativas. E que essa
tarefa nãor seja
responsabilidade apenas
da aula de Língua
Portuguesa, mas também
das demais disciplinas [...]
O professor precisa ser
mediador nesse processo
[...], deverá organizar
planos de aula com
atividades que
possibilitam a utilizar a
linguagem na produção de
textos orais e escritos.

A partir de uma dada situação, dever-seia induzir os alunos à percepção de como efetivamente a fala e o vocabulário do professor poderia enriquecê-los linguisticamente. Retirar o aluno do coloquialismo e levá-lo à formalidade objetivando desenvolver neste indivíduo o discernimento quanto ao uso das variantes linguísticas de acordo com a situação exigida é a premissa da evolução perceptiva e cognitiva da comunicação.

Retomando a análise dos dados observados e organizados na entrevista, tratarse-á os alunos pelas iniciais A1, A2, A3, A4, A5 e A6 para melhor elucidação. Iniciou-se a conversa, com o grupo de estudantes, expondo a finalidade dessa pesquisa e a importância que cada um deles teria para a realização da mesma. 
Perguntou-se se eles já ouviram e perceberam alguma fala de seus professores em desacordo com as regras gramáticas regidas pela norma culta, A2, disse que ouviu de um deles falas do tipo: "Tragam os exercícios pra mim corrigir.", "Entrem todos pra dentro!", "Nóis quer que vocêis passem no ENEM." Ao indagá-lo sobre como o mesmo avalia o domínio linguístico de seu professor, o aluno respondeu perceber que "ele não sabe falar direito, a gente aprendeu na aula de português que não pode falar entrar pra dentro."

Ainda no que foi indagado aos alunos, cinco dos seis estudantes, A1, A2, A4, A5 e A6, disseram que apesar de perceberem "erros" na fala dos professores, a comunicação é boa e o diálogo acontece basicamente sobre os assuntos pertinentes à escola e às matérias lecionadas. Admitem o fato de que poderiam aprender melhor o que é exposto se os professores oferecessem textos interpretativos próximos à realidade deles. O material didático utilizado é composto por apostilas oferecidas pelo Estado.

A preferência pelas matérias foi bem diversificada do ponto de vista dos alunos e o motivo pelo qual preferem tais matérias também. Quando perguntado sobre quais seriam suas matérias favoritas, o aluno A1 confessa preferir a matéria de biologia porque gosta muito da professora. $\mathrm{O}$ aluno $\mathrm{A} 2$ prefere matemática, pois consegue fazer cálculos "de cabeça" e tem bastante facilidade com números. Já o aluno A3 admite gostar mais de educação física, afinal desde pequeno joga bola e pratica atividades físicas. Os alunos A4 e A5 se interessam por história porque entendem melhor a matéria do jeito que o professor explica e o aluno A6 apontou muito interesse pela matéria de sociologia pelo fato de se interessar pelas questões existenciais do mundo como ele mesmo afirma. Curiosamente, nenhum dos alunos entrevistados esboçou interesse por português.

Por unanimidade, eles concluíram que conseguem compreender conceitos trabalhados em outras disciplinas com o conhecimento que possuem em língua portuguesa quando questionado como a língua portuguesa contribui para o aprendizado de outras matérias, porém admitem que muitas palavras geram dúvidas diante de leituras e, às vezes, seus professores não sabem esclarecê-las.

Quanto aos educadores, esses serão referidos por P1, P2, P3 e P4. Inicialmente, foi solicitado que informassem sua formação acadêmica. Os mesmos possuem curso de licenciatura plena na área em que atuam e apenas P2 estendeu sua formação com pósgraduação. Quanto à formulação do plano de aula, todos afirmam utilizarem-no com base no plano de ensino formulado no início do ano letivo, entretanto P1 confessa que raramente é elaborado um plano de aula completo.

Em resposta à pergunta sobre como trabalham a oralidade e a escrita em sala de aula, P3 e P4 disseram não corrigir desvios da norma culta em suas provas porque acreditam que estariam "misturando as matérias" e pensam que devem avaliar o conhecimento do aluno quanto ao que the foi proposto pelas disciplinas que ministram. P1, ao contrário dos colegas, disse que corrige seus alunos verbalmente sem expô-los e aponta certos desvios em provas e trabalhos escritos. P2 assegurou trabalhar a oralidade e a escrita padrão fazendo correções dos exercícios e entende que a interpretação de textos ajuda muito no entendimento de sua matéria e já observou que quanto maior a capacidade interpretativa do aluno, maior sua facilidade em resolver as atividades propostas.

Perguntados sobre como avaliam sua comunicação verbal com os alunos, P1 considera razoável, tenta usar uma linguagem considerada "correta" e faz analogias para facilitar a compreensão dos alunos. Todos responderam evitarem o uso de gírias por considerarem inadequado e pouco construtivo. P3 apontou para o fato de que a maioria dos alunos demonstra vocabulário restrito. Em consonância à resposta, $\mathrm{P} 4$ relatou que em suas aulas escuta as conversas dos alunos e constatou o uso predominante da linguagem coloquial, com excessos de gírias e até palavras de baixo calão.

Durante o diálogo, P4 relatou espontaneamente que em sua formação acadêmica não foi preparado e orientado quanto à utilidade prática de conhecimento linguístico. Levando essa questão aos outros docentes, todos concordaram com o colega alegando que em seus cursos de licenciatura não se abordou essa questão. Diante dessa problemática, P3 responsabilizou as instituições de ensino superior em não darem a devida atenção quanto a este fator ao formularem as diretrizes que regem a composição dos cursos de licenciatura vinculada ao papel docente.

Quando perguntado sobre em que a língua portuguesa e seu conteúdo linguístico contribuem na prática de ensino de suas 
disciplinas, apenas P1 e P2 responderam. O primeiro concluiu que a língua é indispensável para o bom desempenho de quaisquer disciplinas e o segundo exemplificou quão proveitoso seria se seus alunos tivessem maior domínio interpretativo e que ele próprio tem certa dificuldade em contextualizar situaçõesproblema.

À coordenadora pedagógica coube a parte da entrevista compreendida quanto ao projeto político-pedagógico (P.P.P) adotado pela escola. Com a finalidade de traçar o caminho a ser percorrido ao longo do ano letivo e direcionar os docentes na prática de ensino, ela afirma que "o objetivo do P.P.P é definir que tipo de escola desejamos e, assim, definir o tipo de cidadão que desejamos formar". Tal projeto "busca a compreensão dos problemas e visa buscar um novo rumo, uma direção". Problemas esses mencionados como sendo evasão escolar e repetência. Ela alega que a escola dá todo o amparo aos professores na formulação de seus planos de aula e que realizam trocas de experiências, sugestões de atividades e palestras no momento do Horário de trabalho pedagógico coletivo (HTPC).

Perguntada sobre como a coordenação avalia o domínio linguístico na prática de ensino do corpo docente, a mesma disse: "a maioria dos professores tem bom domínio da língua, mas é necessário que os professores de todas as disciplinas trabalhem com recursos metodológicos diversificados como cartazes, revistas, jornais, cartas de edital, etc. para que os alunos consigam aprender a ler e a escrever adequadamente". Ainda nessa temática, ela admite que alguns educadores possuem dificuldades para realizarem atividades desse tipo e falham no desempenho intertextual da língua materna.

\section{CONSIDERAÇÕES FINAIS}

Este estudo buscou analisar como é trabalhada a linguagem em sala de aula e o domínio linguístico dos professores, independentemente da matéria que ministram, considerando a norma culta como variante linguística essencial para a construção cultural do indivíduo em formação. Constatou-se a predominância pelo coloquialismo, principalmente, na modalidade oral.

Apropriar-se da linguagem informal de maneira que aproxime o aluno do professor é válido e pedagogicamente recomendado, porém deixar de oferecer ao aluno uma modalidade mais complexa e construtiva o leva a estagnação cultural. Percebeu-se que mesmo dentro desta variante mais simples e habitual, existe certo limite entre o aceito e o grosseiro. Os discentes demonstraram capacidade perceptiva ao analisarem falas que não correspondem com as normas que regem a normativa culta da língua. Tal fato leva à conclusão que os mesmos conseguem assimilar e se posicionarem diante do que é aceito ou não dentro do contexto discursivo ensinado e proposto pela Língua Portuguesa na sua variante culta.

Pode-se observar a insuficiência linguística na formação acadêmica. As instituições de ensino superior deveriam considerar que um dos atributos que tornam um professor apto à prática docente é seu domínio diante da oratória e que quem domina tal técnica deve se apropriar da gramática normativa. Assim, necessita-se adequar metodologia de ensino pedagógico com formação acadêmica de qualidade para construir o entendimento de que a língua materna favorece e possibilita a transmissão de conhecimento indispensável para formação de professores qualificados e conscientes do seu papel como educadores.

Observou-se que a coordenação escolar sugere uma proposta de projeto que conscientiza seu quadro docente diante da importância que se deve prestar à afetividade pelo ensino da língua interdisciplinarmente. Persistir neste tema garantiria melhores resultados e, consequentemente, educadores mais amparados linguisticamente.

Conclui-se que o domínio linguístico na prática de ensino possibilita o entendimento e a apropriação da língua, em suas mais distintas variantes, tornado o aluno um ser pensante $\mathrm{e}$ atuante em uma sociedade que exige capacidade de dominar gêneros discursos diversificados.

\section{REFERÊNCIAS}

ASSOCIAÇÃO BRASILEIRA DE NORMAS TÉCNICAS. Informações e documentação: citações em documentos: apresentação. NBR 10520. Rio de Janeiro: ABNT, 2002.

BAGNO, Marcos. Preconceito linguístico. 0 que é, como se faz. 4. ed. São Paulo: Loyola, 2007. Disponível em: <http://www.professorjailton.com.br/home/bibli oteca/preconceito_linguistico_marcos_bagno.pdf >. Acesso em: 29 jan. 2018. 
Norma Linguística, Hibridismo \& Tradução. Traduzires, v.1, maio/2012. Disponível em:

<http://repositorio.unb.br/bitstream/10482/105 46/1/ARTIGO_NormaLinguisticaHibridismo.pdf>. Acesso em: 29 jan., 2018.

BECHARA, Evanildo. Em defesa da Gramática. 2011. Disponível em : <http://www.cursocriar.com/_arquivos/criarfazdi ferenca_artigos/em_defesa_da_gramatica.pdf $>$. Acesso em: 02, fev., 2018

BRASIL. Lei de Diretrizes e Bases da Educação Nacional. Lei no 9.394/96, de 20 de dezembro de 1996. Disponível em: < http://www.planalto.gov.br/CCIVIL_03/Leis/L939 4.htm.> Acesso em: 17 ago. 2018.

BRASIL. Ministério da Educação. Secretaria da Educação Básica. Departamento de Políticas de Ensino Médio. Orientações curriculares pra o Ensino Médio. Brasília: MEC, 2006. V.1.

BRASIL. Ministério da Educação. Secretaria da Educação Média e Tecnológica. Parâmetros Curriculares Nacionais: Ensino Médio, Ciências da Natureza, Matemática e suas Tecnologias. Brasília: MEC, 2000. V.3.

BRASIL. Ministério da Educação. Secretaria da Educação Média e Tecnológica. Parâmetros Curriculares Nacionais: Ensino Médio, Linguagens, Códigos e suas Tecnologias. Brasília: MEC, 2000. V.3

COSERIU, E. Sincronia, diacronia e história. Rio de Janeiro/São Paulo: Presença/EDUSP, 1979.

JUNQUEIRA, F.G.C. (2003). Confronto de vozes discursivas no contexto escolar: percepções sobre o ensino de gramática da língua portuguesa. Dissertação (Mestrado em Letras) pelo Departamento de Letras da Pontifícia Universidade Católica do Rio de Janeiro. 2003, p.66. Disponível em: http://www.maxwell.vrac.puc-

rio.br/4009/4009 1.PDF e <htt:// https://www.maxwell.vrac.pucrio.br/4009/4009 5.PDF>. Acesso em: 04 set. 2018
LIBANÊO, J. C. Proposta didática. Concepções de Escola, Ensino e Aprendizagem, 2017. Disponível em:

<http://autoresdoensino.blogspot.com.br/2011/

12/proposta-didatica-concepcoes-de-

escola.html>. Acesso em: 15, out. 2017.

LIBÂNEO, J. C. Didática. Campinas- SP: Papirus, 1990.

OLIVEIRA, A.; ORTEGA, J.; MOLOGNI, M. Normas e Padrões para Trabalhos Acadêmicos e Científicos da Unoeste. 3. ed. eletr. rev. ampl. Presidente Prudente: Unoeste, 2018.

PIANA, M. C. A construção do perfil do assistente social no cenário educacional [online]. São Paulo: Editora UNESP; São Paulo: Cultura Acadêmica, $2009 . \quad$ Disponível em: <http://books.scielo.org/id/vwc8g/pdf/piana9788579830389-06.pdf>. Acesso em: 02 fev. 2018.

RIBEIRO, M. L. O ensino de gramática: uma prática sem sentido? Revista da UEFS, v.1, n. 10, jul./dez., $1992 . \quad$ Disponível em: <http://www2.uefs.br/sitientibus/pdf/10/o_ensi no_de_gramatica_uma_pratica_sem_sentido.pdf >. Acesso em: 07, out., 2017.

TERRA, E. Minigramática. 11. ed. São Paulo: Editora Scipione, 2006

Recebido para publicação em: 22/04/2018

Revisado em: 17/05/2018

Aceito em: 06/07/2018 